\title{
A Monte Carlo Simulation and Fuzzy Delphi-Based Approach to Valuing Real Options in Engineering Fields
}

\author{
Roberta Pellegrino and Nicola Costantino \\ Politecnico di Bari - Dipartimento di Ingegneria Meccanica e Gestionale
}

Italy

\section{Introduction}

The success of a firm depends on its ability to manage uncertainty of investment projects and strategies it decides to make or develop. During the management of new projects, routines and technologies, its constant objective should be to earn increasing returns by exploiting opportunities and limiting losses that could be created by uncertainty. Thus, firms must carefully recognize and evaluate the actions to be taken to respond to uncertainty. To help managers in their decision-making process in uncertain environments, new techniques and theories have been developed. One of them is the real option theory, where a real option is the right, not the obligation, to take some action in the future (Dixit and Pindyck, 1995). The formal approach, which originated from financial models, deals with future uncertainty and opportunities a firm can seize, and aims at valuing the flexibility that often managers have to "react" to uncertainty. In this sense, the real option potential to estimate the value of this flexibility is appealing for managers. As Leslie and Michaels (1997) report, in fact, over the past years, the theory has drawn a growing body of literature and has gathered support across the business world in academia, consulting, and the corporation. Copeland and Weiner (1990) of McKinsey observe that the "use of options methodology gives managers a better handle on uncertainty".

Despite the growing support the real option theory has been attracting in academia and its apparent relevance in business decisions, few corporate managers and practitioners have truly recognized or applied the power of real options in managing their businesses (Leslie and Michaels, 1997; Lander and Pinches, 1998). In other words, the application of real options to managerial practice is poor, and is often limited to a conceptual level. Several reasons could explain why real options are not widely used in practice, as some studies analyzed (Lander and Pinches, 1998; Borison, 2003; and others). Anyway, all these reasons could be traced back to a fundamental issue, that is, the "financial" origin of the real option theory and their evaluation models.

From a practical standpoint, real option modeling learned from the financial world is not easy to use or implement as real world cases are often reasonably sophisticated and complex. The inputs required for the application of these models (with financial features) 
are often not defined or easy to define in the real world. Thus, in order to adapt financial option-based models to the real world, the complexity of these models must be reduced so that they become mathematically tractable. This implies the need for making a variety of simplifying assumptions. For example, option-based models are severely limited if there are more than one or two sources of uncertainty. In the presence of two or more uncertainties, therefore, they are usually modeled in such a way that they are combined and then treated as a single uncertainty. Furthermore, in real world cases these uncertainties have technical (engineering) - economical features rather than financial ones. These and other "adaptation assumptions" make Real Option Pricing (ROP) models a black box for managers, and de facto limit their transparency.

The present chapter presents the results of a research aimed to develop a methodological approach to analyze and assess real options in real world investment opportunities. It combines in a consistent and original way two well-known techniques, namely the Monte Carlo simulation for real option pricing and the fuzzy-Delphi method for eliciting, when historical data miss, probabilistic input parameters from the knowledge of even more than one expert in a consistent, structured and transparent way.

The chapter is organized as follows. The next section presents an overview on real options, their origin, characteristics as well as the challenges in their use by practitioners. Section 3 presents the new approach based on the Monte Carlo simulation proposed for evaluating managerial flexibility. Section 4 explains how to elicit uncertain parameters from experts when historical data are unavailable. Section 5 provides an application of the proposed approach, and finally conclusions and future works end the chapter.

\section{Real option theory: State of art}

All projects are subject to uncertainty, arising from diverse sources (including technical, management and commercial issues, both internal and external to the project). Project managers widely recognize that successful management of uncertainty is intimately associated with project success, since the proactive project manager constantly seeks to steer the project towards the achievement of the desired objectives (Hillson, 2002). Investment decisions that are at the core of any development strategy imply - to some extent - taking the hard choice to sink economic resources now, in the hope of future benefits, betting on the distant and uncertain future horizon (European Commission, 2008). Traditional investment decisions are characterized by irreversibility and uncertainty about their future rewards. Once money is spent, it cannot be recovered if the payoffs hoped for do not materialize. These decisions are typically made by using traditional project evaluation approaches, such as those based on Discounted Cash Flows (DCF) analysis. They assume implicitly that a project will be undertaken now and operated on continuously at a set time scale, until the end of its expected useful life, even though the future is uncertain. Therefore, they are "static" and underestimate the upside value of investment (Kogut and Kulatilaka, 1994) by assuming management's passive and inflexible commitment to a certain "operating strategy". They are also "deterministic" since they make implicit assumptions concerning a certain "expected scenario" of cash flows. In the real world, because of uncertainty and competitive interactions, the realization of cash flows will probably differ from what management originally expected. 
As new information is available and uncertainty about the market conditions and future cash flows is gradually resolved, management should revise the operating strategy it originally anticipated in order to achieve the initial desired goals (Boute et al., 2004). However, unexpected events during the project management can have a range of effects on achievement of project objectives, from the total disaster to the unexpected welcome surprise. Thus the role of the managerial flexibility to adapt in response to new information is not only limiting downside losses relative to the initial expectations under passive management (uncertainty with negative effects), but also improving the upside potential of the investment by the exploitation of favorable events (uncertainty with positive effects). In a competitive market/environment like the global one, it is unlikely that a project or, more in general, a firm can succeed by formulating and following a detailed long-term plan and operating strategy rigidly (Yeo and Qiu, 2003). As Coy (1999) reported, Hewlett-Packard Co. CEO Lewis E. Platt said, at the end of the last millennium, "anyone who tells you they have a 5- or 10-year plan is probably crazy. This is the age of scenario planning. You need not only speed but agility". Hence, traditional managerial techniques arisen from stable environments are in crisis since they cannot capture the value of the flexibility in changing the operating strategy to capitalize from favorable opportunities or to cut losses in the case of adverse development (Olafsson, 2003). A better valuation approach to support decision making in uncertain environments, indeed, should incorporate the uncertainty and the active decision making required for a strategy to succeed (Luehrman, 1998). Hence, it is essential that flexibility be quantified. Any attempt to quantify this flexibility leads almost naturally to the concept of options (Trigeorgis, 1996), i.e., each source of flexibility is, in technical terms, a "real option".

A lot of progress that have been done in the real option literature have changed the way of thinking about an investment opportunity. During project management, managers may make several choices about project characteristics every time new information from market is available. A real option is the way to respond to market changes. This possibility that managers have to adapt their decisions to the change of market has value that must be considered during the decision making process. In other words, this flexibility creates "options" that increase the value of the project and determines the failure of the traditional techniques. Real options originate from the concept of financial options, since they are defined as options written on real assets. Typical real options are the option to hold or abandon a project, the option to decide the timing of investment, the option to choose the production technology, inputs and outputs, the option to reduce or expand the production capacity (Amram and Kulatilaka, 1999). The two next sections discuss these two kinds of options. Of course, the financial world is not as the real one. Therefore, when the theory is applied to the real world, this difference should be considered. Sections 2.3-2.5 discuss some practical issues concerning the application of techniques traditionally used for financial options to model and value the real ones.

\subsection{Financial options}

The concept of real option has its roots in the theory of financial options. An option is a contract that gives the holder the right - not the obligation - to buy or sell a predefined quantity of an underlying asset at a specific price, called strike price or exercise price, at or before the expiration date of the option (maturity). The holder (buyer) pays a price for this 
right (Damodaran, 2001). There are two types of options: call options and put options that respectively give the holder the right to buy or put the underlying asset. There are also American options and European options: the first can be exercised every time before the expiration date, while the latter can be exercised only at the expiration date. The option (call) will be exercised only if the value of the asset is higher than the strike price, on the contrary the option will never be exercised and will expire worthless.

If the option is exercised, the buyer buys the stock at the strike price; hence, the gross profit of the option is the difference between the value of the underlying asset and the exercise price. The net profit on the investment is the difference between the gross profit and the cost to have this right, i.e., that one initially paid for the call (namely option premium (Yeo and Qiu, 2003)). Therefore if $K$ is the strike price and $S_{T}$ is the asset value, the payoff of a call option is $\max \left(S_{T}-K ; 0\right)$, while the payoff of a put option is $\max \left(K-S_{T} ; 0\right)$. The Figure 1 illustrates a payoff diagram for call and put options.

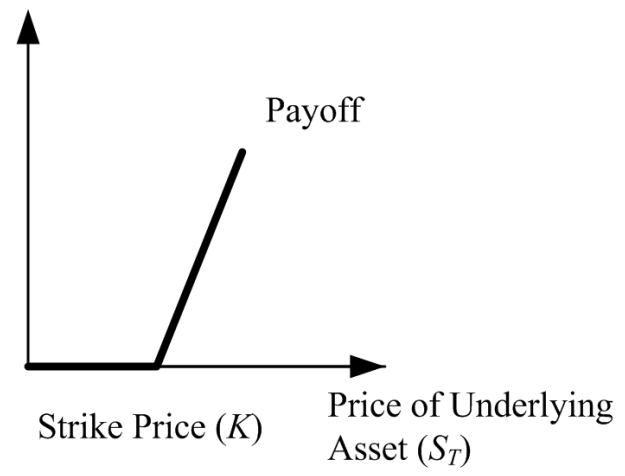

(a) Call Option

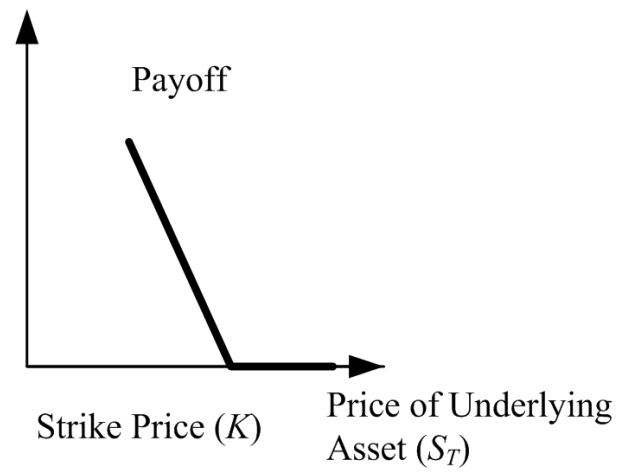

(b) Put Option

Fig. 1. Payoff of call and put options

\subsection{Real options}

In the seventies, some authors started to observe that the concept of option and, consequently, the methods for valuing financial options could be applied to evaluate flexibility associated with physical investments. The first who recognized the analogy between financial options and the flexibility of real world investments was Myers (1984). For this relationship, he coined the expression real option, that is, an option "written" on a real asset. He stated that real options are options on real assets while financial options are options on financial assets. Real options in option thinking are based on the same principles as financial options. Having a real option means to have "the possibility for a certain period to either choose for or against something, without binding oneself up-front" (Yeo and Qiu, 2003). However, the similarity between real and financial options does not mean that they are the same. The major difference is that real options are applicable to real assets (Kumar, 1996). A real asset is usually something tangible, such as a factory, machinery, engineering system, etc., while a financial asset typically consists of stocks, bonds, currency, etc. There are also other important differences that must be taken into consideration when the option pricing tools, built ad hoc for financial options, are used for evaluating real options: 
1. Financial options have a shorter life (less than 1 year to expiration), while real options last more (even some options never expire).

2. Financial options are options on underlying assets that can be traded. Contrarily, real options often are on non-traded assets. Of course, the fact that financial options relate to traded assets simplifies the parameters' estimation. For instance, it is possible to calculate the variance of stock return rate from historical data or other options on the same asset.

3. Financial options are simple since they involve a simple option with only one constant exercise price. Contrarily, the exercise price of a real option can vary randomly. Furthermore, more than one option can be on the same underlying asset.

4. Both kinds of options assume that risk (i.e., the uncertainty of underlying asset) is exogenous. This is true in the financial world, since the uncertainty about the rate of return of a share cannot be influenced by who negotiate options on that asset. In the case of real options, indeed, this is not completely true. The behavior of a company, holder of a real option, can influence competitors and, then, the uncertainty of the specific project.

5. A financial option is a contract, that is, an agreement between two parties (respectively, holder and writer) to be executed later according to the ways set by it. In particular, the holder, paying today an amount of money called option premium, acquires the possibility to take some actions in the future (e.g., the right to buy (or sell) the asset on which the call (or put) option is written at a predefined price, called exercise price). The writer has the obligation to meet the holder's requirement. In the case of real options, the situation is deeply different. A real option, in contrast, is not a "contract" between two parties, rather than the possibility that management has to take some actions during project management (e.g., delay or abandon the project, etc.). In other words, it is the higher cost paid to increase the future flexibility of the investment project. Real options represent, in fact, the opportunity that uncertainty offers to the manager to "actively" manage the projects, reacting to changing competitive scenario. During project management, several situations that differ from those expected can arise, new information can be acquired, etc. The uncertainty resolution allows managers to adapt their choices to new circumstances. This is what makes decision-making process flexible and eliminates the irreversibility that characterizes traditional "static" now-or- never decision-making (e.g., if the company does not make the investment now, it will lose the opportunity forever). This flexibility of the decision-making process can be included into the evaluation of a project investment through real options analysis. Thus it is clear that, contrary to financial options, state that a real option is a contract "written" on an asset has a pure analogical meaning.

\subsection{Evaluating real options: Empirical evidence}

Hartmann and Hassan (2006), in a study on the application of real option analysis for pharmaceutical R\&D project valuation, identify two different ways of using the Real Option Analysis (ROA). The first modus of usage can take place in a pure conceptual manner (Real Options Reasoning, ROR). In this case, emphasis is attributed to the innovative management philosophy rather than new calculation methods. "This 'application as a concept' aims to provide a more holistic analysis of the project features from an option's perspective" (Hartmann and Hassan, 2006). The second utilization is based on the first one. After 
identifying all relevant options in the project, the real option methodology is employed for concrete valuation procedure (ROP).

As for ROR, there are no problems since lots of studies clearly defined what a real option is and the associated managerial flexibility. As far as ROP is concerned, because of the importance of the theme and the need for including real options into the decision-making process, a huge study by researchers has been made during the years. It aims at identifying the best way of modeling and valuing the managerial flexibility (or real options) and, consequently, the right investment strategy. The Black-Scholes formula is one of the most known of these options valuation techniques. It seems very simple to use (it is just a formula application), even though the underlying assumptions are not understood or applicable to the real cases. The binomial tree proposed by Cox et al. (1979) is another financial approach largely used in the real option world. Maybe it is more emphasized than the Black-Scholes formula since it can be used to price American options. Another approach for assessing financial options is that one proposed by Longstaff and Shwartz (2001).

Unfortunately, however, the assumptions underlying most of these approaches and the appropriate conditions for their application to real cases are often not spelled out or differ widely from approach to approach and are even contradictory. Furthermore, the difficulties in implementing such approaches as well as their pros and cons are not explained.

Other approaches were developed to overcome the limits of the assumption underlying traditional financial approaches. The so-called "revised classic approach" (Borison, 2003) states explicitly that the assumptions underlying real options are restrictive. They suggest, therefore, that "the classic finance-based real options approach can be applied where these assumptions apply, while management science-based approaches, such as dynamic programming and decision analysis, be applied where they do not" (Borison, 2003). In particular, real options should be used where investments present only public risks, while dynamic programming or decision analysis where investments are dominated by private risks (Dixit and Pindyck, 1994; Amram and Kulatilaka, 2000). It is clear that "the primary, conceptual difficulty with the revised classical approach is separating all investments, in various shades of grey, into black and white, namely 'all market risk' and 'all private risk"' (Borison, 2003). Nau and McCardle (1991) and Smith and Nau (1995) study the relationship between option pricing theory and decision analysis and demonstrate that the two approaches yield the same results when applied correctly. Smith and Nau $(1995)$ and Smith and McCardle $(1998,1999)$ proposed a method that integrates the two approaches. Such method bases on the assumption that there are two types of risk associated with most real investments: public or market risks, which can be hedged by trading securities and valued using option pricing theory, and private risks, which are project-specific risks and can be valued using decision analysis techniques. However, while the McCardle-Nau-Smith approach has a natural appeal in contexts where the distinction between markets risks and project specific risks is very natural (e.g., oil and gas exploration projects), there are several situations or industries where the distinction between market risks and project-specific risks is not as sharp (Brandão et al., 2005).

\subsection{Challenges to the practical implementation of modeling and valuing real options}

As previously discussed, during the last decades, a growing body of literature has been dedicated to real options because of the importance of this theme and the weakness of 
traditional approaches (such as DCF) in an uncertain environment. Despite the growing attention to real options in theory, there is a little application of real options in practice. Companies and managers do not or rarely use real options in managing their businesses (Hartmann and Hassan, 2006). In their 2001 book Real Options: A Practitioner's Guide, coauthors Copeland and Antikarov predicted that real options would supplant NPV in just 10 years. "That prospect seems even more unlikely today" (Teach, 2003). In fact, in 2000 Bain \& Co. conducted a survey about the use of 25 management tools by senior executives across more than 30 industries. This survey reveals that only $9 \%$ out of 451 participants use ROA and $32 \%$ of them, who had used real-options until then, abandoned this tool in 2000 (Teach, 2003). Another survey conducted by Ryan and Ryan (2002) found that in a sample of 205 Fortune 1000 firms only $11.4 \%$ use ROA as an auxiliary method compared with $85.1 \%$ for sensitivity analysis and $66.8 \%$ for scenario analysis. As far as "basic" capital budgeting tools are concerned, NPV is on the top of the list with $96 \%$ (Teach, 2003). The reason for this small use of real options probably may be that real option approach does not describe how manager has to take a decision (Lander and Pinches, 1998). It is necessary to specify that any decision making tool cannot give the best solution because it cannot substitute for managerial experience, knowledge or critical reasoning.

Lander and Pinches (1998) state that there are three primary reasons explaining why current models to evaluate real options are not used in practice. First, the models for evaluating real options are arcane. They are not well known or understood by managers and practitioners. Managers are not conversant with the mathematics of these models. Second, the models currently used originate from the financial world. Consequently, many of the required assumptions are often violated in the real world. This limits the use of real option approach and the reliability of the results. For example, option pricing models - typical of the financial world - have been extended to real investments. Since it is difficult to predict the future value of underlying asset, they assume that this value follows a stochastic process. Binomial model assumes that it is a binomial multiplicative process, but it is no sure that this hypothesis is correct and realistic. Furthermore, if this hypothesis is assumed to be valid, it is necessary to estimate the (financial) parameters of the model which is a difficult task. Third, these models are very complex from a mathematical perspective. Such complexity increases when the number of options embedded in the project increases, and their reciprocal dependence too. Thus a series of simplifying assumptions is usually made. As a consequence, the use of these models and the reliability of the results are limited. For all these reasons it is probably difficult for the managers or practitioners to model real investment opportunities which present real options with these techniques. There should be more attention to the practical side of modeling decision making process so that even those who are not too skilled can use these methods (Lander and Pinches, 1998).

\subsection{Development of new approaches}

The limits of the traditional financial techniques for evaluating real options have encouraged lots of academics to develop and explore new techniques to be used in the real world applications and engineering systems.

One of these is an approach based on a combination of Monte Carlo analysis and genetic algorithm. It can be used to find solutions in cases with a very large number of possible 
futures and system designs (Zhang et al., 2008). For example, Lazo et al. (2003) use this approach to finding an optimal decision rule for oil field development alternatives that may help decision-making with regard to developing a field immediately or waiting for better market conditions. This optimal decision rule is formed by three mutually exclusive alternatives which describe three exercise regions along time, up to the expiration of the concession of the field. This approach is well suited to the design problem of complex engineering system where there are a lot of design alternatives and the benefit and costs of each of them are known. Genetic algorithms, in fact, provide an effective means to solve very large, non-complex, path dependent problems (Hassan and de Neufville, 2006). However, one of the major limits of this approach is the difficulty that mangers can have in handling with tools like genetic algorithm. This maybe justifies the little use in practice of it.

Johnson et al. (2006) proposes system dynamics models for applying real options to practice in the oil and gas industry. They discuss why they can be considered useful for evaluating projects with real options. System dynamics is able to realistically model many systems that use real options while relaxing common assumptions of perfection used by traditional real option models. They state that "modeling realistic managerial behavior in development projects is an area where system dynamics is well suited and has seen extensive application. [. . .] This capability can be used to develop models of managerial behavior when evaluating the purchase or exercise of a real option. [. . . In addition to the basic decision rule for exercising the option, system dynamics can model other influences on managerial exercise choices, such as incentives, delays and biases, and nonlinearities". However, while the authors believe that system dynamics can help real options transition from theory to practice, they think that this is not the single solution to the challenges facing real options use. While the use of system dynamics has been increasing over the past several years (especially in the academic world), its use has not become common place. This can be in large part due to the unfamiliarity of project managers with system dynamics.

de Neufville et al. (2006) present a spreadsheet approach to valuing "real options" in projects. The model avoids complex financial procedures and, therefore, should be readily accessible to practicing professionals responsible for engineering design and management. It involves three steps:

- Step 1 It consists in determining the most likely projections of future costs and revenues of the project, and calculating the economic value. The design that maximizes the NPV is the base case against which flexible solutions are compared.

- Step 2 It consists in simulating possible scenarios in order to explore the effect of uncertainty. The collection of NPV obtained provides the distribution of possible outcomes for a project as well as an expected NPV.

- Step 3 The effects of various ways to provide flexibility are analyzed by changing the costs and revenues to reflect the design alternatives. The difference between the resulting best expected NPV and that of the base case is the value of flexibility.

The authors demonstrate the ease use of the method through a practical application to the design of a parking garage. Designers can take advantages of possible growth by building expansion flexibility into design. For example, they can make the columns big enough to 
support additional levels, should demand justify expansion of the parking garage in later years. In this case, the decision to construct an extra floor was made if the capacity was less than the demand for two consecutive years. This approach is surely valuable due to its easiness of applications. At the same time, however, it does not include the essence of the real options that is the exercise of the option or flexibility whether it is convenient according to the benefits and costs generated by this decision. Furthermore, the decision-making could be more complex than just observing the level of demand, and it should also cope with several uncertainty sources and variables. The next section discusses how Monte Carlo methods can be applied to overcome the problems of the traditional financial option pricing models.

\section{Monte Carlo simulation for real option pricing}

This section proposes an approach based on the Monte Carlo simulation as a possible way of evaluating managerial flexibility while accomplishing this objective. In the following subsections, a conceptual framework to apply it to real world cases is presented, and the pros and cons of this approach are discussed.

\subsection{Monte Carlo simulation}

The idea of Monte Carlo calculation is a lot older than the [digital] computer (Newman and Barkema, 1999). Stanistaw Ulam, a Polish-born mathematician who worked for John von Neumann on the Manhattan Project in 1944 and Edward Teller on the hydrogen bomb in 1951, is credited with inventing the modern Monte Carlo technique in 1946 (Parr and Smith, 2005). The first paper published using the term "Monte Carlo" was written by Metropolis and Ulam, "The Monte Carlo Method", Journal of the American Statistical Association, in 1949. It is considered a powerful and flexible tool, even though quite old; hence, it has been applied to a variety of fields.

The Monte Carlo method can solve a problem by simulating directly the physical process, and is not necessary to write down the equations that describe the behavior of the system (Figure 2). This technique involves the random sampling of each probability distribution within the model to produce hundreds or even thousands of scenarios (also called iterations or trials). Each probability distribution is sampled in a manner that reproduces the distribution's shape.

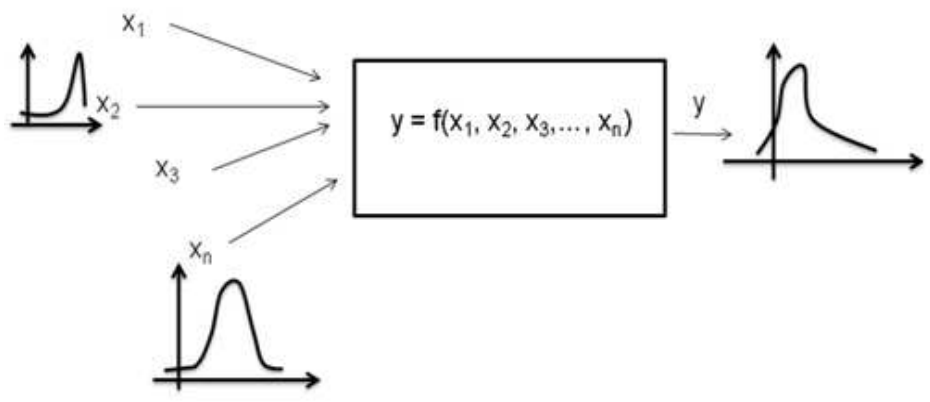

Fig. 2. Monte Carlo simulation 
The distribution of the values calculated for the model outcome therefore reflects the probability of the values that could occur (Vose, 1996). The main elements of the techniques are briefly the following:

1. Input data: the inputs of the model that should be identified by the analyst. They can be known and fixed, namely deterministic, or uncertain, namely probabilistic.

2. Output variables: the results or objectives of the simulation. In other words, they represent what the analyst would like to estimate.

3. Model: the set of equations that describe the relationships between input and output. They translate the working of the system into "mathematical terms". Figure 3 illustrates key elements of the simulation.

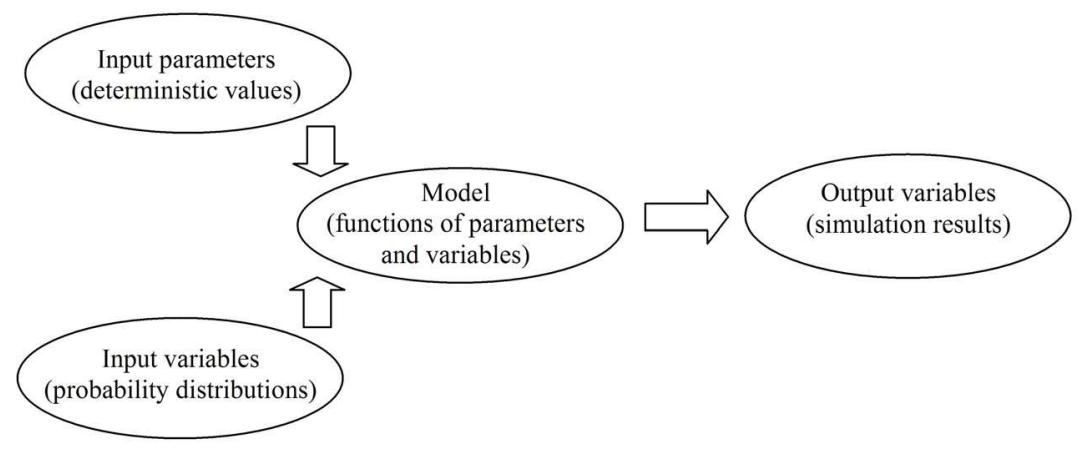

Fig. 3. Elements of the Monte Carlo simulation

The Monte Carlo method builds on the consideration that a direct analytical solution of the problem could be too burdensome or even impossible. The problem is then solved numerically: a "quite high" number $N$ of possible combinations of values that input variables can assume is produced. Then the output is calculated by using model's equations. In order to have each of these combinations, a value for each input variable is generated randomly according to its probability distribution and the possible correlation among variables. Such procedure is repeated $N$ times, with a quite high value of $N$ to have sense from a statistical point of view. These values represent a sample of values for the output variables, and therefore can be used to build their probability distributions.

\subsection{Real Option pricing with Monte Carlo simulation}

Real options can be categorized as those that are either "on" or "in" projects (de Neufville, 2002). "Real options 'on' projects are financial options taken on technical things, treating technology itself as a 'black box'. Real options 'in' projects are options created by changing the actual design of the technical system" (Wang and de Neufville, 2005). Generally speaking, in financial problems that involve options, it is sufficient to correctly model the (stochastic) evolution of the underlying activity over time (e.g., the share price) and decide whether to exercise the option just looking at its value. The determination of the stopping rule is relatively simple. Such assumption could make sense for real options "on" projects (Wang and de Neufville, 2005), even though real options cases present always more sources of uncertainty than financial options. 
Contrarily, real options "in" projects are much more complex and difficult to define in real projects or strategies. In this case, it is not sufficient to model the underlying asset as a whole or a black box. Instead, each source of uncertainty and the relationships among them should be described, as well as the decisional rules that lead to the decision of exercising or not the option whether some events occur, or some variables reach specific levels or values which make convenient the option exercise, and so on. To model simply the evolution of the whole underlying activity over time as a black box has no more sense. It is necessary, instead, to model the system with its real features, and include the decision maker's behavior and reaction to changing situations. To understand the nature of real options "in" project deeply, a simple example from Wang and de Neufville (2005) can be considered. A spare tire on a car "gives the driver the 'right, but not the obligation' to change a tire at any time, but this right will only rationally be used when the car has a flat". It is evident the difference between this kind of option and, for example, the option to abandon or delay a project. In the first case, we should model the system and decision maker's behavior that will decide to change the tire whether there is really a flat, the change in that place and moment is economically advantageous, and so on. In the second case, it would make sense, in order to use a financial approach, modeling the (stochastic) evolution of the project value (as a black box) and deciding to exercise the abandonment option, for example, when the salvage value is higher than the project value. Sometimes, however, this could be a too strong assumption also for real options "on" projects.

Real options in general, and particularly those "in" projects, require, therefore, a deep understanding of the project with its own characteristics. Such knowledge is not readily available among options analysts. This has determined few analyses of real options "in" projects, despite the managerial flexibility is very often more similar to a real option "in" rather than "on" projects. Moreover, since the data available for real options "in" projects are of much poorer quality than that of financial options, real options "in" projects are different and need an appropriate analysis framework. Furthermore, there are typically several uncertainties in a real option evaluation. They are of different kind, such as technical, economic and not only financial. They are often correlated and not independent.

For all these reasons, this research investigates and proposes an original approach based on the Monte Carlo simulation (MCS) for real option pricing. It starts from the traditional concepts of option pricing, but, by using simulation, it takes into consideration multifarious uncertainty sources (as they are in the real world).

As discussed, most of the traditional methods are one/two factors models; they assume that only one/two (financial) inputs are uncertain. Given the characteristics of financial investment decisions, these methods generally are limited to evaluating price uncertainty only. Differently, the MCS is a powerful tool that considers the flexibility in the number and specification of the uncertainties in the decision problem (Triatis and Borison, 2001). MCS is able to include different (theoretically "endless") sources of uncertainty in the evaluation of investment projects. A probability distribution, resulting from historical data (if available) or managers' subjective experience, is assigned to each uncertainty or variable model input. Instead of a single "deterministic" value, the MCS gives a "more realistic" probabilistic representation of the model outputs that managers can use with other considerations to support their decision-making process, and, of course, justify the greater initial investment required by this kind of "flexible" projects. The MCS-based approach can model the decision maker's behavior and system through simple equations and decisional rules. 
The Monte Carlo method, in fact, is a numerical approximation technique that can be used to solve any kind of problem regardless of the type of uncertainty or description. As results of simulation, it produces a data sample which can be analyzed using standard statistical tools facilitated by the software performing the MCS. Moreover, compared to other techniques, such as what-if analysis, scenario planning, etc., the MCS handles correlations among variables correctly and easily.

The potential of this method is its flexibility for the user modeling, reducing the problem of "curse of modeling", permitting a large popularization of real options modeling for people without a comprehensive finance knowledge. This method, in addition, can give (probabilistic) results, even when the system complexity does not have closed-form solutions. Table 1 reports a comparison between the Monte Carlo simulation-based approach and traditional financial techniques for option pricing.

\begin{tabular}{|c|c|}
\hline Monte Carlo simulation-based approach & Financial models for real options \\
\hline $\begin{array}{c}\text { Several (theoretically “endless") sources of } \\
\text { uncertainty }\end{array}$ & $\begin{array}{c}\text { One / two factors models: only one/two } \\
\text { (financial) inputs are uncertain }\end{array}$ \\
\hline $\begin{array}{c}\text { Simple modeling of the decision making } \\
\text { behavior and decisional rules for exercising } \\
\text { options according to each source of } \\
\text { uncertainty }\end{array}$ & $\begin{array}{c}\text { Exercise options according to the value of } \\
\text { the whole underlying activity modeled as a } \\
\text { 'black box' }\end{array}$ \\
\hline $\begin{array}{c}\text { Probabilistic output: range of values } \\
\text { corresponding to several possible scenarios } \\
\text { weighted for their probability }\end{array}$ & $\begin{array}{c}\text { Deterministic output: one single value } \\
\text { corresponding to the single scenario } \\
\text { analyzed }\end{array}$ \\
\hline $\begin{array}{c}\text { 'Transparency' and flexibility of modeling } \\
\text { through a simple spreadsheet) }\end{array}$ & $\begin{array}{c}\text { Black box: too many underlying } \\
\text { mathematical assumptions }\end{array}$ \\
\hline$\ldots$ & $\ldots$ \\
\hline
\end{tabular}

Table 1. MCS-based approach versus traditional financial models for real option pricing

Even if MCS is a well known approach, its use in assessing the value of flexibility given by real options embedded in some projects or engineering systems is relatively new and considered only in few fields. The MCS flexibility has fostered some authors to enhance its potentiality in real options evaluation (Wang and de Neufville, 2005; Triantis and Borison, 2001; Chiara et al., 2007), even if it is rarely applied or, in any case, applied in a way that is different from the approach developed by this research. Triantis and Borison (2001) state that the MCS is able to generate a large number of possible scenarios for the underlying project cash flows or value, based on assumed probability distributions for each uncertainty. The real option value can be then calculated for each of these scenarios, and the average of these values is discounted back to the present. They emphasize the MCS potential, but do not explain how managers should apply this technique. In other cases, such as in Copeland and Antikarov (2001), the MCS is used to generate a distribution for the value of an underlying "developed" project using distributions of variables such as price, market share, and market size that determine the project's cash flows and value. This volatility is then used to generate a binomial tree for the evolution of the project's value over time, and the value of an option on the project is calculated by using the binomial option pricing model. Chiara et.al. (2007) apply least-squares Monte Carlo method by Longstaff and Shwartz 
(2001) to quantify the value of a revenue guarantee in BOT (Build-Operate-Transfer) projects. Only recently, de Neufville et al. (2006) have proposed an approach to valuing real options that is no more based on the traditional financial techniques, but on the modeling of the system through the use of a spreadsheet and simulation. It has been developed for including flexibility in the design of engineering systems. For example, the case example used in their paper is the design of a parking garage. In particular, they analyze whether to design footings and columns of the original building of a parking garage so that additional levels of parking can be added. For this case, the decision to construct an extra floor was made if the capacity was less than the demand for two consecutive years. Of course, real options, as way of thinking, are not only concerned with the design of engineering systems, but with any managerial flexibility that could be created by uncertainty. Therefore, this chapter presents an engineering approach to valuating real option "in" projects based on the modeling of the system. At the same time, however, this approach needs to be generalized in order to be applied to all or the most part of real cases with embedded real options.

\subsection{MCS-based approach: Methodological framework}

This section presents the methodological framework of the developed approach. It consists in three basic modules, as shown in Figure 4. The first module (Module 1) refers to the modeling of the considered projects in terms of real options. In other words, the specific project should be analyzed and possible real options (managerial flexibility) identified. This stage is equivalent to the so-called Real Option Reasoning (ROR). This "application as a concept", or as "a way of thinking", aims to provide a more holistic analysis of the project or strategy features from an option's perspective.

Module 1 is basically structured in two elements: (i) the identification of managerial flexibility (real option "on" and "in" projects) and (ii) the definition of the decisional rules for the option exercise (i.e., the conditions that lead the decision maker to consider whether to exercise the option) or, in other words, the construction of the conceptual framework of the option exercise.

The second module (Module 2) is related to the parameters calculation and uncertainty modeling. In particular, it consists in (i) identifying the inputs of the problem, and (ii) categorizing them into deterministic/static (fixed and known with certainty) parameters and uncertain variables whose uncertainty can be modeled by a probability distribution. As for uncertain variables, the probability distribution can be determined from the historical data when they are available (frequency interpretation of probability), otherwise from expert's opinion (subjective probability or degrees of beliefs (possibilistic reasoning)). Moreover, (iii) the possible correlation among variables should be captured in order to obtain a realistic output. The next section discusses the issue of input modeling and the related techniques, and presents the method developed by this research, namely the fuzzy Delphi method ${ }^{1}$. It aims at eliciting information from more experts, while coping with "vagueness" of human language.

${ }^{1}$ Note that fuzzy logic is not compatible with probabilistic logic, which is why it is important to realize that MSC solves the problem numerically and thereby makes these fine distinctions irrelevant as long as the uncertainty can be modeled in one way or the other. 


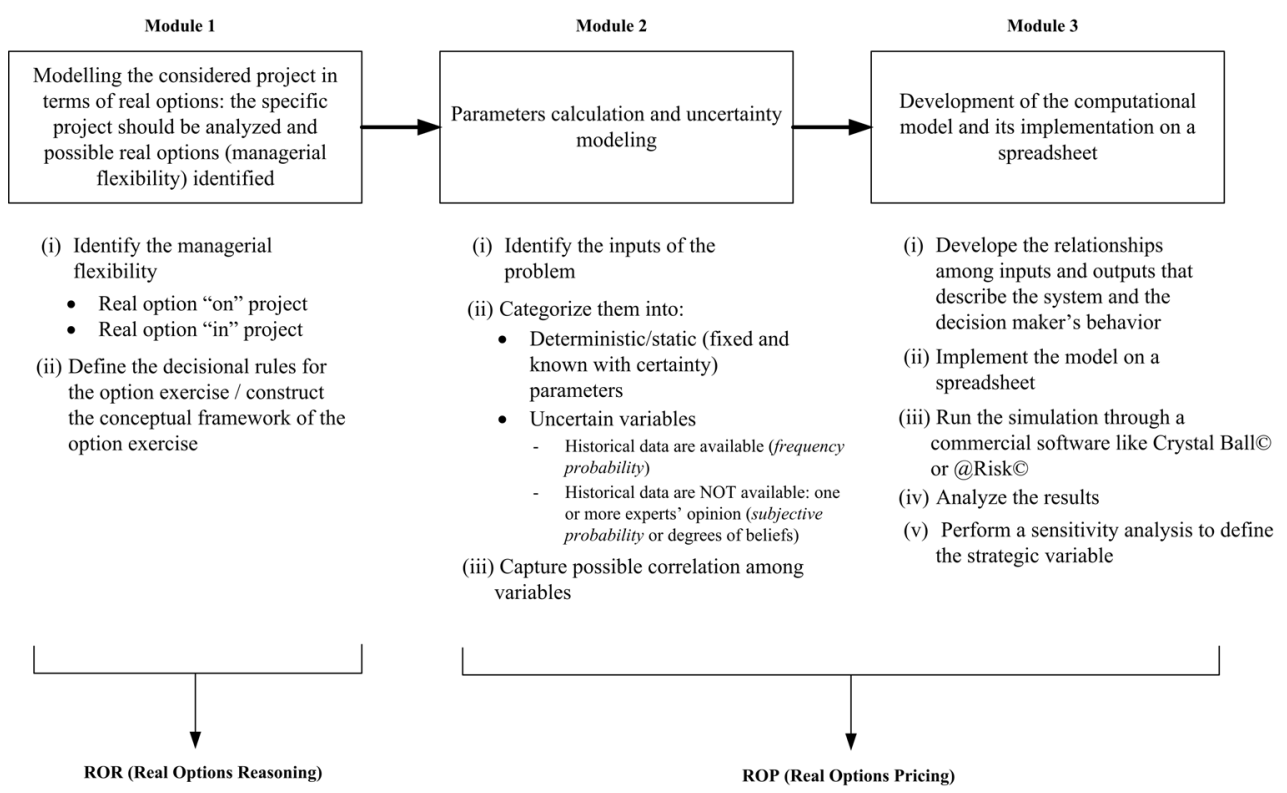

Fig. 4. Methodological framework of modeling

The third module (Module 3) is on the development of the computational model and its implementation on a spreadsheet (or any other environment able to run Monte Carlo simulations). It consists in five basic activities: (i) developing the relationships among inputs and outputs that describe the system and the decision maker's behavior, (ii) implementing the model on a spreadsheet, (iii) running the simulation through a commercial software like Crystal Ball@ or @Risk ${ }^{\circledR}$, (iv) analyzing the results and (v) performing a sensitivity analysis to define the strategic variable.

Module 2 and 3 refers to the Real Option Pricing (ROP). In these last stages, real options have a role of "an analytical tool" whose focus is represented by the concrete evaluation procedures.

\subsection{MCS-based approach for American and European options: Limits and opportunities}

Monte Carlo simulation does not have as many assumptions as the traditional financial real options model. It is possible to specify the probability distributions of the uncertain input data, and describe the function between the input uncertain variables and the output payoff. Then, simulator can do the "brute force" work (Wang and de Neufville, 2005). However, there are some "real or outward" issues about the use of MCS that need to be understood and discussed.

First, if there are multiple sources of uncertainty, it could be prohibitive to calculate the option value at required accuracy. This problem is known as "the curse of dimensionality". It refers to the number of samples per variable which increases exponentially with the number of variables to maintain a given level of accuracy. In 
reality, this problem has been overcome by the high capacity of the modern simulators and the sampling procedures used. Contrarily, this is an "open problem" for the financial real options models. For example, for more than three or four state variables, both lattice and finite-difference methods face several difficulties and are not practical or even not applicable.

Second, one of the main drawbacks of MCS is its "forward" approach rather than "backward". This aspect makes the MCS successful only for European options, while for American option an optimization technique like that developed by Longstaff and Shwartz (2001) should be used. In reality, as this research shows, this limit of the MCS is only outward, and this approach can be used for both European and American real options. European options are past dependent in the sense that cash flows depend only on past information. In this case, MCS values a function by unfolding uncertainty as it evolves from the past (forward induction) (Cortazar, 2001). In the case of American options, the situation is different. American options may be exercised at any of several dates. Thus, cash flows on a given date depend not only on past information, but also on expectations of future events. The value of a security is traditionally obtained by some kind of backward induction. Examples of backward induction procedures have been proposed for valuing assets, from dynamic programming, to binomial and multinomial trees, to finite difference procedures for solving partial differential equations. All these procedures start from some boundary conditions and solve simultaneously for asset value and the optimal exercise policy, determining the shape of the cash flow function in such a way as to maximize asset value. Thus, several studies recognized that the MCS fails in addressing this issue. This research demonstrates that this is not true. In fact, the first aspect to be considered is that in real investment projects, options are often American, in the sense that they can be exercised in any date. Most probably, their exercise is conditioned to the occurrence of some particular events (see the example of the flag in the tire). In other words, they will be exercised whether some events occur, and for some aspects this makes these options equivalent to European options. Moreover, in most real cases American real options can be exercised at any date, but only once during the lifetime of the options. These and other cases can be simply modeled and estimated by MCS. At each trial of the simulation, the simulator chooses randomly input values from their probability distributions. Thus, each trial is a possible scenario that can happen. As really happens, since all input parameters of the problem are known for the scenario, the decision maker will decide to exercise the option if, according to the data, it is allowed and advantageous.

The decisional rule and exercise policy is applied to each scenario (as if it was "deterministic"). Since it is a probabilistic problem, each trial of the simulation will repeat this procedure with the same decisional rule (for the option exercise). The probability distribution of the output payoff will be defined by all outputs of the various scenarios. Thus, for example, one trial will give that the option exercise is, say, at year 3 with its related payoff; another trial will return that the option exercise is at year 5 with its payoff; another will return that the option exercise is not advantageous; and so on. Therefore, it is clear that the simulation output (typically, a probability distribution of the option payoff) is a realistic estimation of the possible option values, and takes into account the "American characteristic" of the option. 
Third, last but not least "concern" about simulation is related to the input parameters of the models. MCS needs to have sound probability distributions and stochastic models for the underlying uncertain variables. If the model inputs, or the model itself, are wrong, the simulation can only serve the role of "garbage in and garbage out" (Wang and de Neufville, 2005). Thus, a correct and reasonable procedure to determine the input data from historical data (if available) or experts' option should be designed.

\section{Uncertainty modeling and input calculation}

The previous section concluded with the discussion about the limits and opportunities of the Monte Carlo simulation-based approach to valuing real options. One of the most critical aspects of the Monte Carlo technique is the determination of the input variables and of their probability distributions. If the distributions of model inputs are wrong, the simulation can only serve the role of "garbage in and garbage out", since the results can be unreliable. Using incorrect or wrong input nullifies, de facto, the advantages of adopting the MCS. This issue sketches the need for developing a method that can be used along with the MCS approach for the calculation and modeling of uncertain input variables. This section accomplishes this objective.

The discussion of uncertainty is closely related to probability, and different conceptions of probability underpin the different ways in which uncertainty has been expressed (Dequech, 2004; Lawson, 1988). One important distinction is that between the theories in which probability is a property of the way one thinks about the world, a degree of belief, and those theories where probability is a property of the real world. Perlman and McCann (1996) use the terms "epistemic" to denote the first type of probability (a degree of belief) and "aleatory" to denote the second type of probability (a feature of reality). The subjective probability theory of de Finetti is example of the former, while frequency theory belongs to the second category (Dequech, 2004).

There are essentially two sources of information used to quantify the uncertainty of the variables within the problem under consideration. The first is available data and the second is experts' opinion. Figure 5 sketches the ways of defining probability distributions of uncertain variables.

The next section presents how to derive distribution probability from data as well as from experts. Then fuzzy logic is introduced the approach used to cope with the vagueness of humane language, even in the presence of more than one experts.

\subsection{Deriving distributions from data}

When observed data for an uncertain variable is available, a distribution that realistically models the true uncertainty can be derived from it. The key assumption is that the observed data can be thought of as a random sample from a probability distribution that should be identified in order to be reproduced in the simulation. In other words, this method is based on the definition of probability based on frequency (frequency probability). The data may come from several sources, such as historical data (time series), surveys, scientific experiments, and so on. The basic steps which should be followed in order to derive a probability distribution are the following: 
Aleatory Unceratinty: The uncertainty can be measured at time of the decision but...
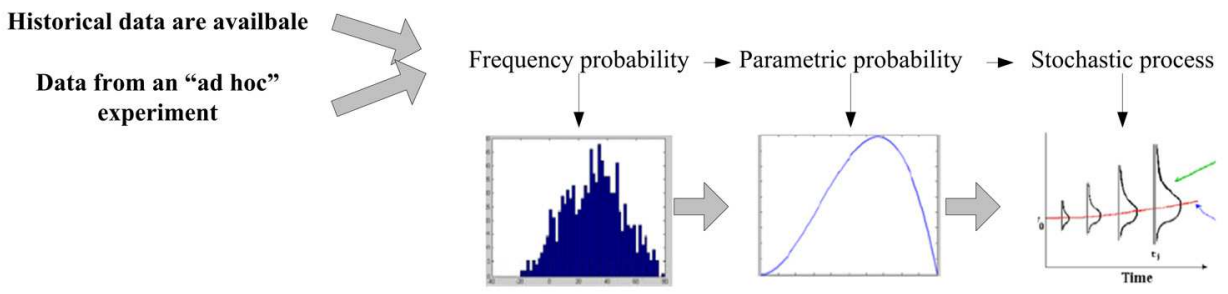

Epistemic Unceratinty: The uncertainty cannot be measured at time of the decision but...

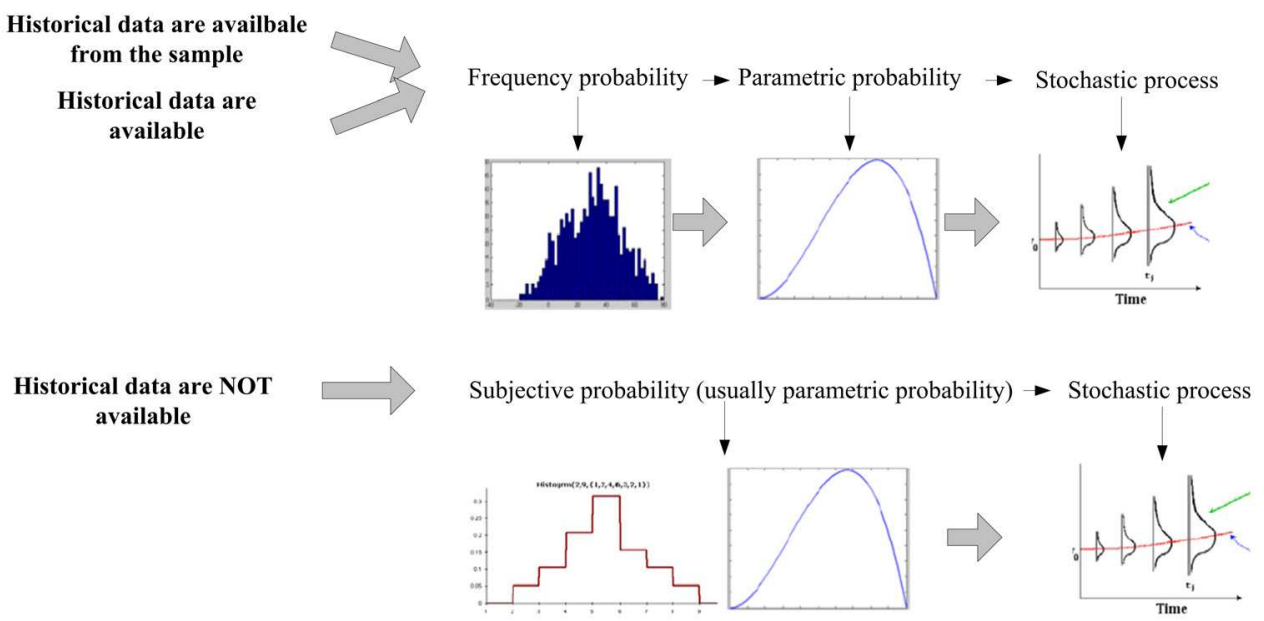

Fig. 5. Project uncertainty and probability distributions (Source: Chiara (2008))

a. Analyzing the available data. The first step should be the analysis of the available data. In particular, (1) it is necessary to understand the nature of the variable or, in other words, if it is discrete or continuous. A variable that is discrete in nature is usually, but not always, best fitted to a discrete distribution. In reality, in certain circumstances, a continuous distribution can describe better the variable. In this case, of course, the value sampled from the distribution should be rounded off in order to be acceptable. It is important to clarify that the reverse never occurs. A continuous variable is always described by a continuous distribution and never by a discrete distribution (Vose, 1996). Then, (2) the range of the variable should be defined. (3) The possible correlations of the variable with another variable within or outside the model should be studied.

b. Fitting a distribution to the available data. The available data can be fitted to an empirical or theoretical distribution. In the first case, starting from the available data the distribution is defined empirically. Usually, a cumulative frequency derived from data is sufficient to define a probability distribution. If the number of data is very large, it is usually easier to arrange the data into histogram form and then define a cumulative frequency. In reality, the availability of software able to automatically attempt fits to several distribution types makes this activity very ease. However, it is also possible to determine the theoretical 
distribution also without this software. The distribution parameters that make a distribution type best fit the available data can be determined in several ways.

c. Goodness-of-fit statistics. The goodness-of-fit-statistics most commonly used are the Chi squared $X^{2}$ and Kolmogorov-Smirnoff $(K-S)$ statistics. They are generally used for discrete and continuous distributions respectively. The lower the value of these statistics, the better the theoretical distributions fit the data. The goodness-of-fitstatistics do not represent the true probability measure that data actually come from the fitted distribution. Instead, they represent the probability that random data generated from the fitted distribution would have produced a goodness-of-fit statistic value as low as that calculated for the observed data. In particular, the Chi squared $X^{2}$ statistic measures the degree of comparability between the expected frequency of the fitted distribution with the frequency of a histogram of the observed data. The K-S statistic measures the maximum vertical distance between the cumulative distribution function of the fitted distribution and the cumulative distribution of the data.

\subsection{Defining distributions from expert opinion}

In most cases, insufficient data is available to completely specify the uncertainty of a variable; hence, one or more experts will usually be consulted to provide their opinion of the variable's uncertainty. This approach is clearly based on the subjective probability definition. Probability distribution functions are typically divided into two categories: nonparametric and parametric distributions. A parametric distribution is based on a mathematical function whose shape and range is determined by one or more distribution parameters. Sometimes, these parameters do not have a direct relationship to the distribution shapes. Examples are Normal, Beta, Lognormal, and so on. Nonparametric distribution, instead, have a direct and intuitive relationship between their parameters and their shape or range. Examples are Uniform, Triangle, Discrete, and so on. Therefore, "as a rule, non-parametric distributions are far more reliable and flexible for modeling expert opinion" (Vose, 1996). However, when the expert is very familiar with using the parameters that define the distribution or the parameters of a parametric distribution are intuitive (such as for Binomial distribution), the use of parametric distributions is preferred to the non-parametric ones in modeling expert opinion.

One of the distributions mostly used to model expert opinion is the BetaPERT distribution. It is useful to point out this distribution since it is relatively new and especially used in risk analysis. Strictly speaking, it is a parametric distribution, but it has been adapted so that the expert should only provide estimates of the minimum, most likely and maximum value for the variable. Examples of BetaPERT are shown in Figure 6.

The equation of the BetaPERT distribution is related to the Beta distribution, as in (1).

$$
\operatorname{BetaPERT}(a, b, c)=\operatorname{Beta}\left(a_{1}, a_{1}\right)(c-a)+a
$$

where:

$$
\begin{gathered}
a_{1}=[(\mu-a)(2 b-a-c)] /[(b-\mu)(c-a)] \\
a_{2}=a_{1}(c-\mu) /(\mu-a)
\end{gathered}
$$

The mean $\mu=(a+4 b+c) / 6$ 
As shown in (4), the mean for the BetaPERT distribution is four times more sensitive to the most likely value than to the minimum and maximum values. Consequently, the expected value is less sensitive to minimum and maximum values than triangular's expectation.

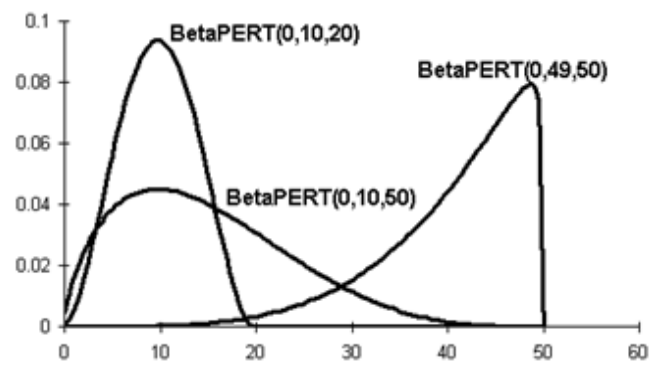

Fig. 6. Examples of BetaPERT distributions

\subsection{Fuzzy set theory and fuzzy logic}

When the value of a variable has to be determined by experts' opinions, it is necessary to consider that human propositions and reasoning can be affected by "vagueness and nonspecificity" (Klir, 1995). In fact, "an economic agent does not generally manifest a perfect aptitude to clearly discriminate between the alternatives he prefers and those he does not prefer. Even if he is well informed, it does not follow that his behavior obeys a binary logic of the type: preference-non preference, as in the classical theory" (Ponsard, 1988). Human reasoning and decision making is very often based on genuine uncertainty embedded in natural language. Economic agent, in fact, expresses his experience or predictions in "imprecise" linguistic terms, such as: "The price of oil is not likely to increase substantially in the near future" (Klir, 1995). Thus classical two-valued logic often is not able to model economic reality and human reasoning. In this sense, fuzzy logic provides a natural framework to express and deal with this kind of vagueness.

Fuzzy set theory and fuzzy logic, therefore, address a fundamentally different class of problems from that addressed by probability theory. Probability theory deals with propositions that are mutually exclusive. There is simply uncertainty as to which is true. The real number attached to the proposition is a measure of how much we believe a certain proposition to be true. Conversely, fuzzy set theory deals with proposition that have "vague meaning". In fuzzy logic, a proposition may be true or false up to a certain degree: the interval between 0 (false) and 1 (true) describes human reasoning. For example, if we consider the previous statement "the price of oil is not likely to increase substantially in the near future" (Klir, 1995), the expression "not likely" is a statement of uncertainty and can be represented by a probability. However, although the terms "increase substantially" or "near future" are not precise, they are not an expression of uncertainty. We assume that we can measure the increase and know how large it is. The question is how much the increase's particular size fits the economic agent's vague description of "increase substantially". Zadeh (Yager et al., 1987) addresses such problems with fuzzy set theory. Fuzzy set theory associates a real number between 0 and 1 with the membership of a particular element in a set. Let $U$ be a collection of objects denoted generically by $u$, which could be discrete or continuous. $U$ is called the universe of discourse and $u$ represents the generic element of $U$. 
A fuzzy set $F$ in a universe of discourse $U$ is characterized by a membership function $\mu_{F}$ which takes values in the interval $[0,1]$, namely $\mu_{F}: U \rightarrow[0,1]$. A fuzzy set may be viewed as a generalization of the concept of an ordinary set whose membership function only takes two values 0,1 . Thus a fuzzy set $F$ in $U$ may be represented as a set of ordered pairs of a generic element $u$ and its grade of membership function: $\mathrm{F}=\left(u, \mu_{F}(u)\right) \mid u \in U$. In this sense, "the use of fuzzy sets provides a basis for a systematic way for the manipulation of vague and imprecise concepts" (Lee, 1990).

Fuzzy sets can be employed to represent linguistic variables. A linguistic variable can be regarded either as a variable whose value is a fuzzy number or as a variable whose values are defined in linguistic terms. A linguistic variable is characterized by a quintuple $(x$, $T(x), U, G, M)$ where $x$ is the name of the variable; $T(x)$ is the term set of $x$, i.e., the set of names of linguistic values of $x$ with each value being a fuzzy number defined in $U$; $G$ is a syntactic rule for generating the names of values of $x$; and $M$ is a semantic rule for associating with each value its meaning. For example, if speed is interpreted as a linguistic variable, then its term set $T$ (speed) could be $T$ (speed) = slow, moderate, fast, very slow, more or less fast, ..., where each term in $T$ (speed) is characterized by a fuzzy set in a universe of discourse $U=[0,100]$. The term "slow" can be interpreted as "a speed below about $40 \mathrm{mph}$ ", "moderate" as "a speed close to $55 \mathrm{mph}$ ", "fast" as "a speed above about 70 mph" (Lee, 1990). These terms can be characterized as fuzzy sets whose membership functions are shown in Figure 7.

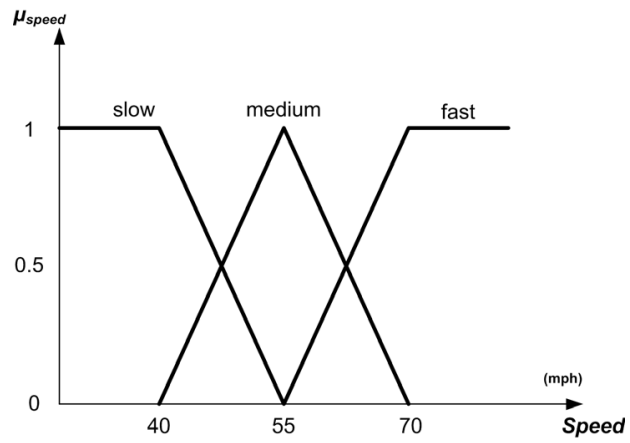

Fig. 7. Diagrammatic representation of fuzzy speeds. "Speed" is linguistic variable with three terms: "slow", "medium" and "fast" (Source: Lee (1990))

\subsection{From one to more experts: The Delphi method}

The Delphi technique is a method of eliciting and refining group judgments. It was developed in the 1950s by the Rand Corporation at Santa Monica, CA. It is a widely used and accepted method for achieving convergence of opinions concerning real-world knowledge by using a series of questionnaires to collect data from a panel of selected subjects (Hsu and Sandford, 2007). The rationale for the procedure is that "two heads are better than one" when the exact knowledge is not available (Dalkey, 1969). This procedure has three key features. First, the response is anonymous, because the opinions of members 
of the group are obtained by a formal questionnaire. Second, it employs multiple iterations that refer to the feedback process. This process consists of a series of rounds. In each round every participant works through a questionnaire which is sent to the coordinator. Then a summation of collected opinions is returned to each participant. Therefore based on the position of the whole group they can modify their initial judgments about the information provided in previous iterations. Third, there is a statistical group response defined by aggregating the individual opinions in the final round. All these features are designed to minimize the biasing effects of dominant individuals, irrelevant communications (noise), and group pressure toward conformity (Dalkey, 1969).

\subsection{The fuzzy Delphi method}

As discussed in previous sections, when insufficient data is available to completely specify the uncertainty of a variable, experts will usually be consulted to provide their opinions of the variable's uncertainty (subjective probability or degree of believes). This implies to cope with the vagueness of experts' judgments and the subjectivity of each opinion. In order to determine the uncertain parameters required by the MCS-based real options model, an approach using both the Delphi technique and the fuzzy logic was developed (Costantino et al., 2009; Costantino and Pellegrino, 2010b; Pellegrino and Costantino, 2011). It is able to take into consideration the vagueness of opinions and, at the same time, to reach a certain degree of "objectivity" by interviewing more experts. The proposed approach modifies that introduced in 1988 by Kaufmann and Gupta and applied by Cheng and Lin (2002) to the decision making. The procedure adopted by the fuzzy Delphi approach identifies two kinds of information that should be elicited from experts:

i. Estimates of uncertain parameters of the model (quantitative variables). As discussed, to model the expert opinion it is preferable to use non-parametric distributions rather than parametric distributions (whose shape and range are determined by one or more distribution parameters that often do not have a direct relationship with distribution's shape). Moreover, one of the probability distributions most commonly used is the BetaPERT distribution. Three-point estimates, therefore, are usually quite sufficient to model an expert's opinion about some uncertain variables (Vose, 1996). In this fuzzy Delphi approach the uncertain quantitative variables were mostly modeled by BetaPERT distribution. Therefore, experts are asked to express their opinion about the three input parameters of this distribution. The procedure can be, of course, easily generalized for all kinds of distributions. Experts are asked to express each of these three values by a "trapezoidal" fuzzy number (one pessimistic, one optimistic and two values that define the "most plausible" interval of values, as illustrated in Figure 8) instead of a crisp number. A trapezoidal fuzzy number was chosen since its membership function is intuitive and easy to understand. However, the membership function can be easily generalized. Therefore, we will have one fuzzy number which describes the minimum, one for the maximum and another one for the most likely value. Each fuzzy number represents a "possibility distribution" (Zadeh, 1978) of the value under consideration (i.e., $\min$, max and most likely). 


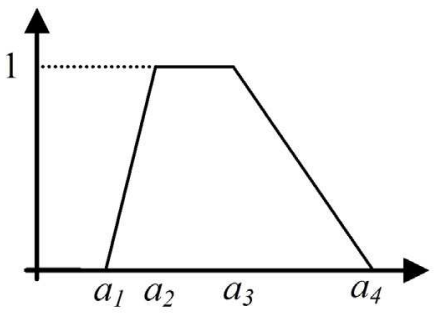

Fig. 8. Example of a trapezoidal fuzzy number $A=\left(a_{1}, a_{2}, a_{3}, a_{4}\right)$

ii. Subjective estimation of discrete probabilities (linguistic variables). An expert will sometimes be asked to provide an estimate of the probability of occurrence of a discrete event. This is a difficult task for the expert. He will have to rely on his feel based on his understanding and perception of this event. This task is often complicated by the difficulty in having to visualize the difference between $30 \%$ and $40 \%$. A way to avoid this problem is to offer the expert a list of probability phrases (Vose, 1996). In the proposed fuzzy Delphi approach each expert is asked to select a phrase that best fits his understanding of the probability of each event that has to be considered, as in Table 2. Using the language of fuzzy number, these probability phrases represent the term set of the linguistic variable (probability of a discrete event). Each value of the term set, i.e., each probability phrase, is a fuzzy number whose membership function is again a trapezoidal one for its simplicity.

\begin{tabular}{|l|c|c|}
\hline Probability phrase & Linguistic Variable & Fuzzy number \\
\hline Almost certain & Very high $(\mathrm{VH})$ & $(0.8,0.9,1,1)$ \\
\hline Highly likely & High $(\mathrm{H})$ & $(0.7,0.8,0.8,0.9)$ \\
\hline Fairly likely & Medium high $(\mathrm{MH})$ & $(0.5,0.6,0.7,0.8)$ \\
\hline Even chance & Medium $(\mathrm{M})$ & $(0.4,0.5,0.5,0.6)$ \\
\hline Fairly unlikely & Medium low (ML) & $(0.2,0.3,0.4,0.5)$ \\
\hline Highly unlikely & Low (L) & $(0.1,0.2,0.2,0.3)$ \\
\hline Almost impossible & Very low (VL) & $(0,0,0.1,0.2)$ \\
\hline
\end{tabular}

Table 2. Probability phrases and fuzzy linguistic variables

The fuzzy Delphi method proposed to determine the final values of the input variables in the model consists of the following steps.

Step 1. Experts $E_{i}, i=1, \ldots, n$ are asked to provide the possible values of the three-point estimates of the considered quantitative variables (i). Each estimate is expressed by a trapezoidal fuzzy number (5): the pessimistic value $a_{1}{ }^{(i)}$, the most plausible interval of values $\left(a_{2}{ }^{(i)}, a_{3}{ }^{(i)}\right)$, and the optimistic value $a_{4}{ }^{(i)}$.

$$
A^{(i)}=\left(a_{1}(i), a_{2}{ }^{(i)}, a_{3}^{(i)}, a_{4}^{(i)}\right) \quad i=1, \ldots, n
$$

The expert is also asked to select a probability phrase for each discrete event he wants to estimate (ii). Each probability phrase is associated with a linguistic variable that corresponds to a predefined trapezoidal fuzzy number, as shown in Table 2. For each question the expert should also give an explanation of his answer, in order to let the coordinator know the main reasons of the choice. 
Step 2. The average value $A_{m}$ of all $A^{(i)}, i=1, \ldots, n$, is computed as calculated by (6).

$$
\begin{aligned}
& A_{m}=\left[\left(a_{1 m^{m i n}}, a_{1 m^{m o d e}}, a_{1 m^{m a x}}\right),\left(a_{2 m^{m i n}}, a_{2 m^{m o d e}}, a_{2 m}{ }^{\text {max }}\right),\left(a_{3 m^{m i n}}, a_{3 m^{m o d e}}, a_{3 m^{m a x}}\right),\right. \\
& \left(a_{4 m}{ }^{\min }, a_{4 m^{m o d e}}, a_{4 m} \text { max }\right)
\end{aligned}
$$

where:

$$
\left.a_{j m}^{\min }=\min _{i=1, \ldots, n} a^{(i)_{j},} a_{j m} \text { mode }=\text { mode }_{i=1, \ldots, n} a^{(i)}\right)_{j}, a_{j m} \max =\max _{i=1, \ldots, n} a^{(i)} j_{j} \quad j=1,2,3,4
$$

Then the average position of the group on the quantitative variable (expressed as "according to the other interviewed experts, the variable $x$ varies in a range between $x_{\min }$ and $x_{\max }$, with a peak in $\left.x_{\text {mode }}{ }^{\prime \prime}\right)$ along with the opinions of other experts on the probability phrases and the main explanations of their answers are sent back to the expert $E_{i}$ for reexamination.

Step 3. In the third round, each expert $E_{i}$ can revise his judgments based on the information discussed at the end of step 2, i.e. he can present a revised trapezoidal fuzzy number for the quantitative variables (8) and modify the probability phrase (linguistic variable) according to the position of the whole group.

$$
B^{(i)}=\left(b^{(i)} 1_{1} b^{(i)_{2}}, b^{(i)_{3}}, b^{(i)}\right)_{4} \quad i=1, \ldots, n
$$

This process starting with Step 2 is repeated. The new average position of the group $B_{m}$ is calculated according to equation (6), where $a_{1}{ }^{(i)}, a_{2}{ }^{(i)}, a_{3}{ }^{(i)}, a_{4}{ }^{(i)}$ are substituted by $b_{1}(i)$, $b_{2}{ }^{(i)}, b_{3}{ }^{(i)}, b_{4}{ }^{(i)}$. The process could be repeated again and again until to successive means $A_{m}, B_{m} \ldots$ become reasonably close and the group almost agrees on the value of the linguistic variables (or, in the worst cases, there are no more changes in the experts' evaluations).

Step 4. If the final opinions are not coincident, the mean can be considered for both the quantitative variables and linguistic ones expressed in terms of fuzzy numbers (9).

$$
\begin{aligned}
& \mathrm{A}_{\mathrm{m}}=\left(m_{1 m}, m_{2 m}, m_{3 m}, m_{4 m}\right)= \\
& \left(\frac{1}{n} \sum_{i=1}^{n} a_{1}^{(i)}, \frac{1}{n} \sum_{i=1}^{n} a_{2}^{(i)}, \frac{1}{n} \sum_{i=1}^{n} a_{3}^{(i)}, \frac{1}{n} \sum_{i=1}^{n} a_{4}^{(i)}\right)
\end{aligned}
$$

The output of the fuzzy Delphi process so far is a fuzzy set, specifying a possibility distribution of the uncertain variable parameters. In defining the probability distributions in MCS model, a nonfuzzy (crisp) value is required. Consequently, one must defuzzify the fuzzy output obtained from the fuzzy Delphi process, namely:

$$
z_{0}=\operatorname{defuzzifier}(z)
$$

where $z_{0}$ is the nonfuzzy output and defuzzifier is the defuzzification operator. The defuzzification method used in this research is the centroid calculation, which returns as a crisp number the center of the area under the curve (fuzzy number). Therefore, the defuzzification value of the trapezoidal fuzzy number for each variable (quantitative or linguistic) is used as input in the model. 


\section{Case study applications}

The described approach was applied to some real cases on different engineering fields (Costantino and Pellegrino, 2010b; 2011; Costantino et al., 2009) in order to show and test its potential in evaluating investment projects that present managerial flexibilities.

One example is represented by the use of the MCS approach for estimating the risks in project finance transactions where contractual structures for allocating risks during the operating period are adopted. Examples are put-or-pay, take-or-pay or take-and-pay, and throughput contracts (Razavi, 1996).

Take-and-pay and take-or-pay are two different off-take agreements: the first requires the buyer to take and pay for the good or service only if delivered, whereas the second requires a payment unconditionally, even if no good or service is provided or producible by the seller. The commitment of all or an agreed percentage of the output capacity of a project through these contracts gives a purchaser supply certainty and, at the same time, provides sales predictability to the project company (Hoffman, 2007). Lenders can also rely upon offtake agreements for repayment of their loans. However, there are also some drawbacks, especially when buyers have highly variable and uncertain cash flows. Even though a purchaser may have obligated itself to purchase a certain capacity of the project, there may be circumstances under which it does not want to take the contracted product or service. According to these contracts, the purchaser should pay the standby charge in any case. In order to reduce this kind of "stiffness" and mitigate the buyer's risk, a source of flexibility is often added in these contracts, that is, the clause named "option capacity". Before an offtake obligor wishing be excused from its purchase obligation is required to pay a standby charge for not taking such product, the withdrawing purchaser's capacity is offered to other purchasers. To the extent that other purchasers exercise their option to pick up and purchase the capacity, the initial purchaser is relieved of a standby charge (Sullivan, 2004). The opportunity, given by the option capacity, to mitigate the buyer's damages when he decides to "abandon" the contract can be worth and should be evaluated by the buyer in order to determine the fair value of the contract.

In order to evaluate the flexibility added by the "option capacity" clause in the take-and-pay and take-or-pay contracts, the problem can be modeled using an approach based on Real Options. According to this approach, the buyer purchases the good for the price $P$ and holds a put option on the good with the exercise price $x$. For example, if the buyer's promise is enforced by damages, then $d$ is the damage and $x$ is the difference between the contract price and this damage (or $P=d+x$ ). In other words, $x$ is the "recovered" value.

Thus the possibility of the buyer to decline to take up its allocation of the product can be modeled as an abandonment (put) option where the damage is the standby charge. Therefore, the difference between the total cost on the purchased amount, as indicated in the contract terms, and the standby charge is the exercise price of the put option, or the "avoided loss". The cost of the other supply source (with the assumption that the business carries on as usual after breaching the contract) represent the underlying asset, by using the real option terminology. In this case the exercise price is not fixed a priori. In fact, with the option capacity clause, the standby charge may not be paid by the initial off-taker if other purchasers decide to exercise their (call) option to pick up the available capacity. This process is illustrated in Figure 8. 


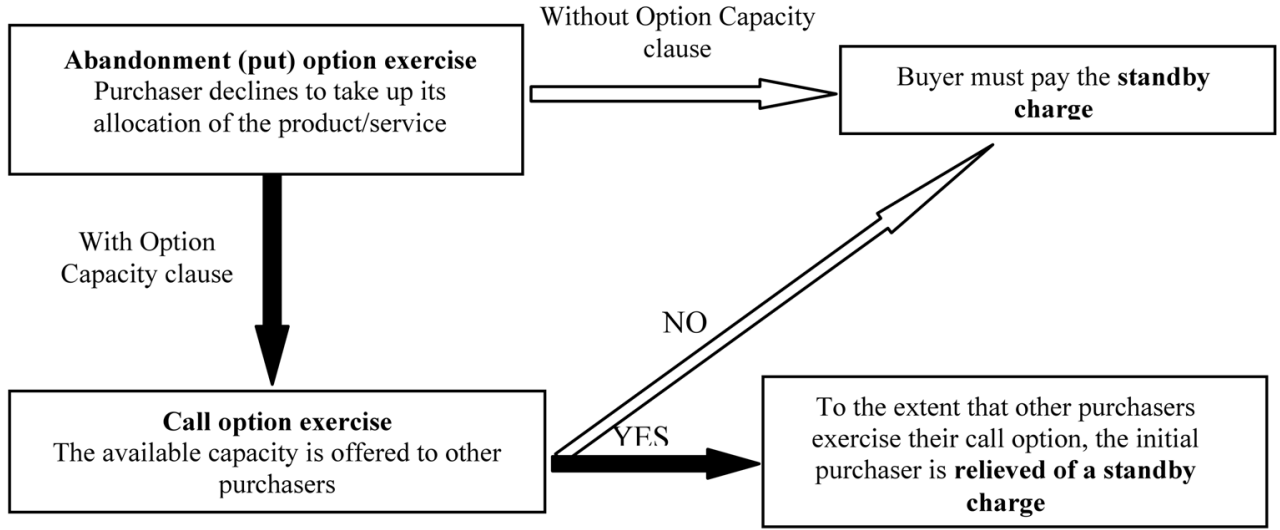

Fig. 9. Model of off-take contracts based on real options

This way, the damage of the purchaser, and therefore its risk, is mitigated and the off-take contract has more value. A computational model was developed for estimating the value of the flexibility given to the off-taker by the option capacity clause in take-or-pay and takeand-pay contracts 2 .

The probabilistic input variables of the model are of two kinds: quantitative variables which were modeled as BetaPert distributions and subjective probabilities of some discrete events.

The experts were asked to give three-point estimates for the variables of the first group in terms of trapezoidal fuzzy numbers rather than crisp numbers, as the example in Table 3 shows.

\begin{tabular}{|l|c|c|c|}
\hline & minimum & most likely & maximum \\
\hline Probabilistic Variable 1 & $\left(a_{1}, a_{2}, a_{3}, a_{4}\right)$ & $\left(\beta_{1}, \beta_{2}, \beta_{3}, \beta_{4}\right)$ & $\left(\gamma_{1}, \gamma_{2}, \gamma_{3}, \gamma_{4}\right)$ \\
\hline$\ldots$ & & & \\
\hline Probabilistic Variable $n$ & $\left(\delta_{1}, \delta_{2}, \delta_{3}, \delta_{4}\right)$ & $\left(\varepsilon_{1}, \varepsilon_{2}, \varepsilon_{3}, \varepsilon_{4}\right)$ & $\left(\eta_{1}, \eta_{2}, \eta_{3}, \eta_{4}\right)$ \\
\hline
\end{tabular}

Table 3. The fuzzy three-point estimates of quantitative variables

The second group includes variables related to the subjective probability of some discrete events. The experts were asked to select for each of these events the probability phrase that best fits their perception. The linguistic variables associated with these phrases are expressed in terms of trapezoidal fuzzy numbers rather than crisp numbers (see Table 2).

The fuzzy Delphi procedure was used for eliciting the required probabilistic variables from experts.

The outputs of the model are probability distributions. In this case they represent the values of the (put) option to breach the contract with and without the option capacity clause as well as the value of the flexibility added to the contract by this clause. They are shown in Figure 10 and 11.

2Details about the model as well as its equations are described in (Costantino and Pellegrino 2011). 


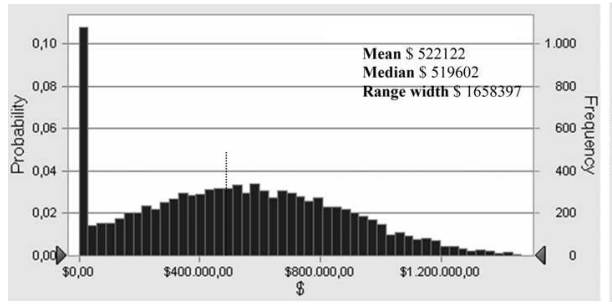

(a)

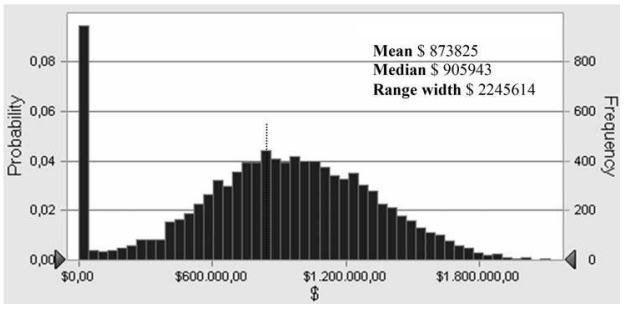

(b)

Fig. 10. Comparison of the value of the option to breach the contract without (a) and with (b) the option capacity clause

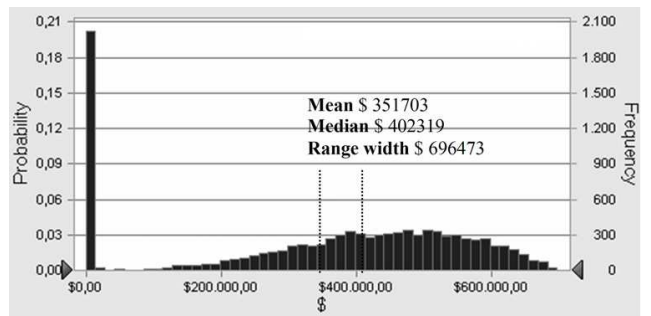

Fig. 11. Benefits given by the option capacity clause

The case shows some limitations of the developed approach. On one hand, in fact, the modeling of the decision making process gives more reliable results than traditional "blackbox" approaches. On the other hand, it could seem to be more sophisticated than the application of a simple formula like the Black-Scholes one, and discourage its use by managers. For this reason, it could be important to apply the approach to several cases in order to give practitioners examples of how to use it.

\section{Future work and closure}

This research has developed a methodological approach to analyzing and assessing the value of real options in real world investments and strategies. The developed approach can be applied to estimating the value of the managerial flexibility (i.e., real options) in any engineering fields characterized by issues and sources of uncertainty that differ substantially from those typical of the financial world where option theory originated. In other words, the approach can be used any time money is spent in order to create a flexible project or strategy able to react to future uncertain events and, consequently, exploit opportunities and limit losses generated by uncertainty.

The proposed approach combines in a consistent and original way two well-known techniques, namely the Monte Carlo simulation for real option pricing and the fuzzy-Delphi method for eliciting, when historical data miss, probabilistic input variables from the knowledge of more than one expert in a consistent, structured and transparent way.

The proposed approach to modeling and valuing real options in real world problems (1) is more practically oriented than the traditional financial techniques, (2) is easier to understand and implement and, therefore, more likely to be used, (3) can model and value 
real cases having multiple uncertainties with multifarious features (such as technical, economic, and so on), (4) can model and simulate decision maker's behavior about the real option (i.e., managerial flexibilities) exercise, (5) can make real option valuation accessible to corporate managers or practitioners, strategists, and other decision makers, which could not have a financial background, (6) can offer a guide or a tool to support the decision maker rather than an exact numerical valuation as in the case of financial methods.

The proposed research has important and practical merits. Foremost, the potential of the methodology developed is its flexibility for the user modeling, reducing the problem of "curse of modelling" and permitting a large popularization of real options modeling for people without a comprehensive finance knowledge. The "transparency" of the approach would make managers able to use real options for estimating the value of the managerial flexibility. Managers can consider and manage the implication of the uncertainty, avoiding "myopic" decisions due to traditional DCF techniques which ignore the managerial flexibility. Findings of this research, and particularly the methodological framework of the MCS and fuzzy Delphi-based approach, are applicable to any problem, which implies real options, encountered in any engineering fields, such as natural resources, manufacturing, business investment, R\&D, and so on. As a consequence, the application of real options to engineering issues, which is now still "confined" to a pure conceptual and theoretical level, just as "way of thinking" (due to the complexity of most of the traditional techniques of real option pricing), could be addressed to a practical level by using this "practically oriented" approach.

Future work will focus on applying the developed approach on several cases from real world in order to tests it and give practitioners examples of how to use it.

\section{References}

Amram, M. \& Kulatilaka, N. (1999). Disciplined decisions: aligning strategy with the financial markets. Harvard Business Review, Vol.77, No.1, pp. 95-104.

Amram, M. \& Kulatilaka, N. (2000). Strategy and Shareholder Value Creation: The Real Options Frontier. Journal of Applied Corporate Finance, Vol.15, No.2, pp. 15-28.

Black, F. \& Scholes, M. (1973). The pricing of options and corporate liabilities. Journal of Political Economy, Vol.81, pp. 637-659.

Borison, A. (2003). Real options analysis: where are the Emperor's clothes? Proceedings of Real Options Seventh Annual International Conference, Washington DC, July 10-12, 2003.

Boute, R.; Demeulemeester, E. \& Herroelen, W. (2004). A real options approach to project management. International Journal of Production Research, Vol.42, No.9, pp. 17151725.

Brandão, L.E.; Dyer, J.S. \& Hahn, W.J. (2005). Using Binomial Decision Trees to Solve RealOption Valuation Problems. Decision Analysis, Vol.2, No.2, pp. 69-88.

Cheng, C.H. \& Lin, Y. (2002). Evaluating the best main battle tank using fuzzy decision theory with linguistic criteria evaluation. European Journal of Operational Research, Vol.142, pp. 174-186.

Cheng, C.H. \& Lin, Y. (2002). Evaluating the best main battle tank using fuzzy decision theory with linguistic criteria evaluation. European Journal of Operational Research, Vol.142, pp. 174-186. 
Chiara, N. (2008). Class Notes for Manage Civil Infrastructure Systems. Columbia University Civil Engineering and Engineering Mechanics.

Chiara, N.; Garvin, M.J. \& Vecer, J. (2007). Valuing Simple Multiple-Exercise Real Options in Infrastructure Projects. Journal of Infrastructure Systems, Vol.13, No.2, pp. 97-104.

Copeland, T. \& Antikarov, V. (2001). Real Options. Texere LLC, New York.

Copeland, T. \& Weiner, J. (1990). Proactive management of uncertainty. The McKinsey Quarterly, Vol. 4, pp. 133-152.

Cortazar, G. (2001). Simulation and numerical methods in real options valuation. Pontificia Universidad Catolica de Chile-General.

Costantino, N. \& Pellegrino, R. (2010a). Choosing between single and multiple sourcing based on supplier default risk: A real options approach. Journal of Purchasing $\mathcal{E}$ Supply Management, Vol.16, pp. 27-40.

Costantino, N. \& Pellegrino, R. (2010b). Evaluating Risk in Put-or-Pay Contracts: An Application in Waste Management Using Fuzzy Delphi Method. Journal of Applied Operational Research, Vol. 2, No. 1, pp. 62-70.

Costantino, N. \& Pellegrino, R. (2011). Risk mitigation in take or pay and take and pay contracts in project financing: the purchaser's perspective. International Journal of Project Organisation and Management, Vol. 3, Nos. 3/4, pp. 258-272.

Costantino, N.; d'Amato, M. \& Pellegrino, R. (2009). A Real Options and fuzzy Delphi-based approach for appraising the effect of an urban infrastructure on surrounding lands. Fuzzy Economic Review, Vol.14, No. 2, pp. 3-16.

Cox, J.; Ross, S. \& Rubinstein, M. (1979). Option pricing: a simplified approach. Journal of Financial Economics, Vol.7, pp. 229-264.

Coy, P. (1999). Exploiting uncertainty: the 'real options' revolution in decision-making. Business Week, Vol.7, No.118.

Dalkey, N.C. (1969). The Delphi method: an experimental study of group opinion. The Rand Corporation, Santa Monica CA.

Damodaran, A. (2001). The promise and peril of Real Options. Stern School of Business, 2001.

de Finetti, B. (1931). Sul significato soggettivo della probabilità. Fundamenta Mathematicae, Vol.17, pp. 298-329.

de Finetti, B. (1968). Probability: the Subjectivistic Approach. In: La philosophie contemporaine, R. Klibansky, (Ed.), La Nuova Italia, Florence, pp. 45-53.

de Finetti, B. (1972). Probability, Induction, and Statistics. Wiley, New York.

de Neufville, R. (2002). Class notes for Engineering Systems Analysis for Design. MIT engineering school-wide elective - Cambridge, MA.

de Neufville, R.; Scholtes, S. \& Wang, T. (2006). Real options by spreadsheet: Parking garage case example. Journal of Infrastructure Systems, Vol.12, No.2, pp. 107-111.

Dequech, D. (2004). Uncertainty: individuals, institutions and technology. Cambridge Journal of Economics, Vol.28, pp. 365-378.

Dixit, A. \& Pindyck, R. (1994). Investment Under Uncertainty. Princeton University Press, Princeton (NJ).

Dixit, A.K. \& Pindyck, R.S. (1995). The options approach to capital investment. Harvard Business Review, pp. 105-115.

European Commission (2008). Guide to Cost Benefit Analysis of Investment Projects. Directorate General Regional Policy, July 2008. 
Harmantzis, F.C. \& Tanguturi, V.P. (2007). Investment decisions in the wireless industry applying real options. Telecommunications Policy, Vol.31, pp. 107-123.

Hartmann, M. \& Hassan, V. (2006). Application of real options analysis for pharmaceutical R\&D project valuation - Empirical results from a survey. Research Policy, Vol.35, pp. 343-354.

Hassan, R. \& de Neufville, R. (2006). Design of Engineering Systems Under Uncertainty via Real Options and Heuristic Optimization. In: Proceedings of Real Options Conference, New York, June, 2006.

Hassan, R. \& de Neufville, R. (2006). Design of Engineering Systems Under Uncertainty via Real Options and Heuristic Optimization. In: Proceedings of Real Options Conference, New York, June, 2006.

Hillson, D. (2002). Extending the risk process to manage opportunities. International Journal of Project Management, Vol.20, pp. 235-240.

Hoffman, S. (2007). The Law and Business of International Project Finance. Cambridge University Press, Third Edition.

Hsu, C.C. \& Sandford, B.A. (2007). The Delphi Technique: Making Sense of Consensus. Practical Assessment, Research \& Evaluation, Vol.12, No.10, pp. 1-7.

Johnson, S.; Taylor, T. \& Ford, D.N. (2006). Using System Dynamics to Extend Real Options Use: Insights from the Oil \& Gas Industry. In: Proceedings of 2006 International System Dynamics Conference, Nijmegan, The Netherlands, July 23-27, 2006.

Klir, G. (1995). Fuzzy Sets and Fuzzy Logic: Theory and Applications. Prentice Hall, Upper Saddle River, N.J..

Kogut, B. \& Kulatilaka, N. (1994). Option thinking and platform investment: investing in opportunity. California Management Review, Vol.36, No. 20, pp. 52-71.

Kumar, R.L. (1996). A note on project risk and option values of investment in information technologies. Journal of Management Information Systems, Vol.13, No.1, pp. 187-193.

Lander, D.M. \& Pinches, G.E. (1998). Challenges to the Practical Implementation of Modeling and Valuing Real Options. The Quarterly Review of Economics and Finance, Vol.38, pp. 537-567.

Lawson, T. (1988). Probability and uncertainty in economic analysis. Journal of Post Keynesian Economics, Vol.11, No.1, pp. 38-65.

Lazo, G.J.; Pacheco, M.A. \& Vellasco, M.B.R. (2003). Real Option Decision Rules for Oil Field Development Under Market Uncertainty Using Genetic Algorithms and Monte Carlo Simulation. In: Proceedings of Seventh Annual Real Options Conference, Washington, DC, USA, July 10-12, 2003.

Lee, C.C. (1990). Fuzzy Logic in Control Systems: Fuzzy Logic Controller - Part I. IEEE Transactions on Systems, Man, and Cybernetics, Vol.20, No.2, pp.404-418.

Leslie, K.J. \& Michaels, M.P. (1997) The real power of real options. The McKinsey Quarterly, Vol.3, pp. 4-22,

Longstaff, F.A. \& Schwartz, V (2001). Valuing American Options by Simulation: A Simple Least-Squares Approach. The Review of Financial Studies, Vol.14, No.1, pp. 113-147.

Luehrman, T.A. (1998). Investment opportunities as real options: getting started on the numbers. Harvard Business Review.

Myers, S.C. (1984). Financial theory and financial strategy. Interfaces, pp. 126-137.

Newman, M.E.J. \& Barkema, G.T. (1999). Monte Carlo methods in statistical physics. Oxford University Press, New York. 
Olafsson, S. (2003). Making decisions under uncertainty - implications for high technology investments. BT Technology Journal, Vol.21, No.2, pp. 170-183.

Parr, R.L. \& Smith, G.V. (2005). Intellectual property: valuation, exploitation, and infringement damages, Wiley, New Jersey.

Pellegrino, R. \& Costantino, N. (2011). Risk Mitigation in Take or Pay and Take and Pay Contracts in Project Financing: the Purchaser's Perspective. International Journal of Project Organization and Management - Special issue on Risk Management in Projects and Enterprises, Vol. 3, Nos. 3/4, pp. 258-272.

Perlman, M. \& Jr McCann, C. (1996). Varieties of uncertainty, In: Uncertainty in Economic Thought, C. Schmidt, (Ed.), Edward Elgar, Cheltenham, U.K.

Ponsard, C. (1988). Fuzzy mathematical models in economics. Fuzzy Sets and Systems, Vol.28, No.3, pp. 273-283.

Razavi, H. (1996). Financing Energy Projects in Emerging Economies. Pennwell Books.

Ryan, P.A. \& Ryan, G.P. (2002). Capital budgeting practices of the Fortune 1000: How have things changed?. Journal of Business and Management, Vol.8.

Smith, J.E. \& McCardle, K.F. (1998). Valuing Oil Properties: Integrating Option Pricing and Decision Analysis Approaches. Operations Research, Vol. 46, No.2, pp. 198-217.

Smith, J.E. \& McCardle, K.F.(1999). Options in the real world: Lesson learned in evaluating oil and gas investments. Operations Research, Vol.47, pp. 1-15.

Smith, J.E. \& Nau, R.F. (1995). Valuing Risky Projects: Option Princing Theory and Decision Analysis. Management Science, Vol.41, No.5, pp. 795-816.

Sullivan, R. (2004). International Project Financing, 4th Edition, Juris Publishing, New York.

Teach, E. (2003). Will options take root?. CFO online, July 1st, pp. 73-76.

Triantis, A. \& Borison, A. (2001). Real Options: State of Practice. Journal of Applied Corporate Finance, Vol.14, No.2, pp. 8-24.

Trigeorgis, L. (1996). Real Options. The MIT Press.

Vose, D. (1996). Quantitative Risk Analysis. A Guide to Monte Carlo Simulation Modelling. John Wiley Sons.

Wang, T. \& de Neufville, R. (2005). Real Options 'in' Projects, Proceedings of Real Options Nineth Annual International Conference, Prise, France, June, 2005.

Yager, R.R.; Ovchinnikov, S.; Tong, R.M. \& Nguyen, H.T. (1987). Fuzzy Sets and Applications: Selected Papers by L.A. Zadeh. Wiley, New York,

Yeo, K.T. \& Qiu, F. (2003). The value of management flexibility a real option approach to investment evaluation. International Journal of Project Management, Vol.21, pp. 243250.

Yeo, K.T. \& Qiu, F. (2003). The value of management flexibility a real option approach to investment evaluation. International Journal of Project Management, Vol.21, pp. 243250.

Zadeh, L.A. (1978). Fuzzy sets as a basis for a theory of possibility. Fuzzy Sets and Systems, Vol.1, pp. 3-28.

Zhang, S.; Buurman, J. \& Babovic, V. (2008). Design of a Maritime Security System under Uncertainty Using an Evolutionary Real Options Approach, Proceedings of $12^{\text {th }}$ Annual Real Options Conference, Rio de Janeiro, Brazil, July 10-12, 2008. 


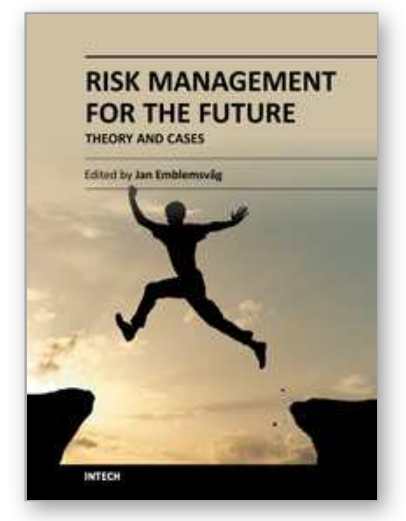

\author{
Risk Management for the Future - Theory and Cases \\ Edited by Dr Jan Emblemsvåg
}

ISBN 978-953-51-0571-8

Hard cover, 496 pages

Publisher InTech

Published online 25, April, 2012

Published in print edition April, 2012

A large part of academic literature, business literature as well as practices in real life are resting on the assumption that uncertainty and risk does not exist. We all know that this is not true, yet, a whole variety of methods, tools and practices are not attuned to the fact that the future is uncertain and that risks are all around us. However, despite risk management entering the agenda some decades ago, it has introduced risks on its own as illustrated by the financial crisis. Here is a book that goes beyond risk management as it is today and tries to discuss what needs to be improved further. The book also offers some cases.

\title{
How to reference
}

In order to correctly reference this scholarly work, feel free to copy and paste the following:

Roberta Pellegrino and Nicola Costantino (2012). A Monte Carlo Simulation and Fuzzy Delphi-Based Approach to Valuing Real Options in Engineering Fields, Risk Management for the Future - Theory and Cases, Dr Jan Emblemsvåg (Ed.), ISBN: 978-953-51-0571-8, InTech, Available from: http://www.intechopen.com/books/riskmanagement-for-the-future-theory-and-cases/a-monte-carlo-simulation-and-fuzzy-delphi-based-approach-tovaluing-real-options-in-engineering-fiel

\section{INTECH}

open science | open minds

\section{InTech Europe}

University Campus STeP Ri

Slavka Krautzeka 83/A

51000 Rijeka, Croatia

Phone: +385 (51) 770447

Fax: +385 (51) 686166

www.intechopen.com

\section{InTech China}

Unit 405, Office Block, Hotel Equatorial Shanghai

No.65, Yan An Road (West), Shanghai, 200040, China

中国上海市延安西路65号上海国际贵都大饭店办公楼405单元

Phone: +86-21-62489820

Fax: $+86-21-62489821$ 
(C) 2012 The Author(s). Licensee IntechOpen. This is an open access article distributed under the terms of the Creative Commons Attribution 3.0 License, which permits unrestricted use, distribution, and reproduction in any medium, provided the original work is properly cited. 